\title{
A Basal Ganglia Pathway Drives Selective Auditory Responses in Songbird Dopaminergic Neurons via Disinhibition
}

\author{
Samuel D. Gale ${ }^{1}$ and David J. Perkel ${ }^{2,3}$ \\ ${ }^{1}$ Graduate Program in Neurobiology and Behavior and Departments of 2 Biology and ${ }^{3}$ Otolaryngology, University of Washington, Seattle, Washington 98195
}

\begin{abstract}
Dopaminergic neurons in mammals respond to rewards and reward-predicting cues, and are thought to play an important role in learning actions or sensory cues that lead to reward. The anatomical sources of input that drive or modulate such responses are not well understood; these ultimately define the range of behavior to which dopaminergic neurons contribute. Primary rewards are not the immediate objective of all goal-directed behavior. For example, a goal of vocal learning is to imitate vocal-communication signals. Here, we demonstrate activation of dopaminergic neurons in songbirds driven by a basal ganglia region required for vocal learning, area X. Dopaminergic neurons in anesthetized zebra finches respond more strongly to the bird's own song (BOS) than to other sounds, and area $\mathrm{X}$ is critical for these responses. Direct pharmacological modulation of area $\mathrm{X}$ output, in the absence of auditory stimulation, is sufficient to bidirectionally modulate the firing rate of dopaminergic neurons. The only known pathway from song control regions to dopaminergic neurons involves a projection from area $X$ to the ventral pallidum (VP), which in turn projects to dopaminergic regions. We show that VP neurons are spontaneously active and inhibited preferentially by BOS, suggesting that area $\mathrm{X}$ disinhibits dopaminergic neurons by inhibiting VP. Supporting this model, auditory-response latencies are shorter in area X than VP, and shorter in VP than dopaminergic neurons. Thus, dopaminergic neurons can be disinhibited selectively by complex sensory stimuli via input from the basal ganglia. The functional pathway we identify may allow dopaminergic neurons to contribute to vocal learning.
\end{abstract}

\section{Introduction}

Dopaminergic neurons in the mammalian substantia nigra pars compacta $(\mathrm{SNc})$ and ventral tegmental area (VTA) are important for motor behavior, some forms of learning, and disorders such as drug addiction. One of their clearest roles is to encode reward prediction errors indicating the presence or potential of reward (Schultz, 1998). These signals motivate reward-procuring actions in real time (Phillips et al., 2003) and are thought to reinforce associations between cues or actions and consequent rewards (Wise, 2004).

It is unknown whether midbrain dopaminergic neurons participate in goal-directed behaviors when the explicit goal is not primary reward (food, sex) or predictors of such rewards. For example, dopaminergic signals could play a role in goaldirected motor learning guided by sensory feedback, such as vocal learning.

Humans and songbirds use auditory feedback to learn how to produce their vocal-communication signals (Doupe and Kuhl, 1999). In songbirds, juveniles learn to imitate an adult's song. Immature vocalizations are highly variable and bear little resem-

Received July 24, 2009; revised Nov. 25, 2009; accepted Nov. 30, 2009.

This work was supported by National Institutes of Health Grants MH066128 to D.J.P. and NS059200 to S.D.G. and by P30 Core Center Grant DC004661.

We thank Drs. Abigail Person and Arthur Leblois for their comments on this paper.

Correspondence should be addressed to David J. Perkel, Departments of Biology and Otolaryngology, University of Washington, 1959 Northeast Pacific Street, HSB BB1165 Box 356515, Seattle, WA 98195. E-mail: perkel@u. washington.edu.

DOI:10.1523/JNEUROSCI.3585-09.2010

Copyright $\odot 2010$ the authors $\quad 0270-6474 / 10 / 301027-11 \$ 15.00 / 0$ blance to the memorized model song. Gradually, as a bird practices and hears himself sing, song quality increases and variability decreases (Derégnaucourt et al., 2005). This suggests a model of song learning in which birds produce variable vocalizations and selectively reinforce neural activity that generates the most successful variants (Fiete et al., 2007).

Most of the "song system" nuclei (Fig. $1 \mathrm{~A}$ ) receive dopaminergic input (Lewis et al., 1981; Bottjer, 1993; Appeltants et al., $2000,2002)$. In particular, the SNc and VTA densely innervate the striatal region area $\mathrm{X}$, which is part of the anterior forebrain pathway (AFP). Via its output to the song motor pathway, the AFP generates song variability and provides instructive signals that adaptively bias vocal output, both of which are critical for song learning (Scharff and Nottebohm, 1991; Ölveczky et al., 2005; Andalman and Fee, 2009). Dopaminergic signals, perhaps reflecting evaluation of predicted or actual auditory feedback, could modulate AFP output and influence song variability and learning.

Do dopaminergic neurons receive song-related input? Tracing studies indicate that telencephalic input to the zebra finch $\mathrm{SNc} / \mathrm{VTA}$ is limited to the parts of the striatum (not including area $\mathrm{X}$ ), the ventral pallidum (VP), and a region of the arcopallium that may receive auditory input (Gale et al., 2008). There are no direct connections from the song system, but area X may make an indirect connection to SNc/VTA via a projection to VP (Fig. $1 A, B$ ) (Gale et al., 2008). However, it is unknown what effect, if any, area $\mathrm{X}$ output has on dopaminergic neurons.

The song system, including area $\mathrm{X}$, and other telencephalic auditory pathways respond to auditory stimuli in urethane- 


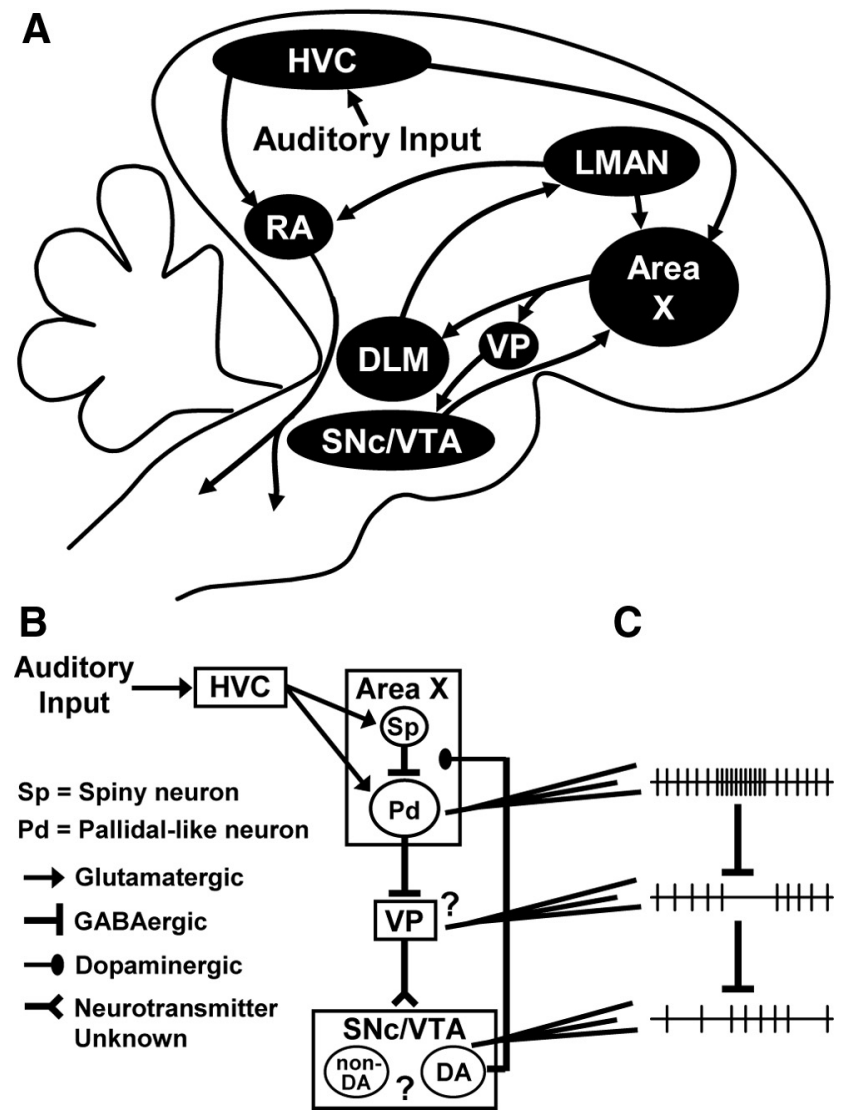

Figure 1. A pathway from the song control regions to dopaminergic neurons. A, Schematic parasagittal view of the zebra finch brain. HVC (proper name) projects to the robust nucleus of the arcopallium (RA) to form a song motor pathway. A separate population of HVC neurons projects to the basal ganglia region area $X$ of the AFP. Area $X$ projects to DLM, which projects to the lateral magnocellular nucleus of the anterior nidopallium (LMAN). LMAN projects to RA and collaterals of these axons project back to area X. Collaterals of area X neurons that project to DLM form terminals in the VP, which projects to the SNc and VTA. The SNc and VTA contain dopaminergic neurons that project densely to area $X$ and surrounding striatum, and sparsely to other forebrain regions including HVC and RA. $\boldsymbol{B}$, Detail of the circuitry addressed in this study. Pallidal-like neurons in area $X$ are GABAergic and project to both DLM (not shown) and VP. Multiple cell types and unknown microcircuitry in VP and SNc/VTA make it difficult to predict the functional consequence, if any, of area $X$ output on VP and dopaminergic neurons (question marks). C, Data presented in Results support a model in which increased activity of area $X$ pallidal-like neurons inhibits spontaneously active, inhibitory projection neurons in VP and thereby disinhibits dopaminergic neurons. Neuronal firing is represented by vertical ticks on a horizontal line.

anesthetized birds (Margoliash, 1983; Doupe, 1997; Theunissen et al., 2004; Person et al., 2007). Neurons in the song system respond preferentially to the bird's own song (BOS). We took advantage of this to test (1) whether VP and SNc/VTA neurons receive auditory input and the selectivity of this auditory input, and (2) the ability of area X to transmit auditory-related (or other) information to dopaminergic neurons. We found that dopaminergic neurons are strongly excited by BOS compared with other sounds and that these responses are likely driven by inhibition of VP neurons by area X.

\section{Materials and Methods}

Song recording and auditory stimuli. All procedures were approved by the Institutional Animal Care and Use Committee at the University of Washington. Before each experiment, the song of an adult male zebra finch $(n=86)$ was recorded in a sound attenuation chamber. Song was sampled at $22.05 \mathrm{kHz}$ using Ishmael sound recording software (David Mellinger, Oregon State University, Newport, OR) and bandpass filtered
(0.1-10 kHz) using GoldWave Audio Editor (GoldWave). The auditory stimuli for electrophysiology experiments were BOS, BOS played in reverse, conspecific song (the song of another zebra finch), heterospecific song (white-crowned sparrow song), amplitude-modulated (AM) noise, and unmodulated noise. The BOS stimulus was the first two motifs from a bout of singing (a motif is a stereotyped sequence of acoustic elements that is repeated during a song bout). Introductory notes preceding the first motif were not included. The duration of BOS stimuli ranged from 0.8 to $2.1 \mathrm{~s}$ (median, $1.4 \mathrm{~s}$ ). Conspecific song was chosen to approximately match the duration of BOS and hence varied for each experiment. The median value of the absolute difference between the durations of BOS and conspecific song stimuli was $9 \mathrm{~ms}(0.6 \%$ of the BOS stimulus duration). Heterospecific song was always the same white-crowned sparrow song (2.0 s duration) (recording obtained from J. Meitzen) (Meitzen et al., 2007). Noise stimuli were generated from a normal distribution and had the same duration, sampling frequency, and bandpass filter setting as the BOS stimulus. AM noise was modulated by the amplitude envelop of BOS; the amplitude envelope was obtained by convolving the rectified BOS waveform with an 88 point $(4 \mathrm{~ms}$ ) Gaussian window. Unmodulated noise had $20 \mathrm{~ms}$ linear onset and offset ramps and the same total power as BOS. Auditory stimuli were presented from a speaker 35 $\mathrm{cm}$ in front of the bird at a peak sound level of $68-72 \mathrm{~dB}$ and randomly interleaved with variable intertrial intervals of $10-15 \mathrm{~s}$.

Surgery, electrophysiology, and juxtacellular labeling. Birds were deprived of food and water for $1 \mathrm{~h}$ and then anesthetized by intramuscular injection of $20 \%$ urethane. The total volume of urethane was $6 \mu \mathrm{l} / \mathrm{g}$, which was divided into three injections with $30 \mathrm{~min}$ between injections. Birds were placed in a stereotaxic apparatus in a sound attenuation chamber with the beak holder (David Kopf Instruments) rotated downward from the horizontal plane by $64^{\circ}$. Lidocaine $(1 \%)$ was injected below the scalp before craniotomies were made above targeted brain regions. Ear bars were removed after cementing the skull to a metal post.

Recording coordinates relative to the bifurcation of the midsagittal sinus were as follows (in $\mathrm{mm}$ ): area $\mathrm{X}$ (anterior, 3.5-4.0; lateral, 1.7-1.9; depth, 3.5-4.2), VP (2.4-2.9, 1.1-1.4, 4.4-4.9), and SNc/VTA (0.2-0.8, $0.5-1.0,6.0-6.5)$. We targeted the region of VP that receives input from area X [described by Gale et al. (2008)]. Striatal regions surrounding area $\mathrm{X}$ also project to VP; although this projection is broadly topographic, there is some overlap of terminals from area $\mathrm{X}$ and surrounding striatum in VP (Person et al., 2008). The zebra finch SNc and VTA form a continuous group of dopaminergic neurons, and there are no known differences between the more anterior and medial VTA and the laterally extending SNc. There is broad topography in both their input from the striatum and VP and their dopaminergic output to the striatum (Person et al., 2008). Neurons that project to area $X$ are abundant in the lateral half of VTA and most of SNc, and at least $95 \%$ of these neurons are dopaminergic (Person et al., 2008). In contrast to the rat VTA, the zebra finch SNc and VTA do not contain a significant (if any) population of nondopaminergic neurons with an otherwise dopaminergic neuron-like phenotype (Cameron et al., 1997; Margolis et al., 2003, 2006; Ungless et al., 2004; Gale and Perkel, 2006). In this regard, the zebra finch VTA is more like the zebra finch and rat SNc than the rat VTA. For the purposes of this study, we typically refer to the zebra finch SNc and VTA as one structure.

Single-unit extracellular recordings were made using glass electrodes with tips broken to $1-3 \mu \mathrm{m}$ diameter. Electrodes were filled with $0.5 \mathrm{M}$ $\mathrm{NaCl}$. Voltage signals were amplified $10 \times$ with an Axoclamp 2B amplifier (Molecular Devices) in bridge mode, and then filtered $(0.1 \mathrm{kHz}$ high pass; $7 \mathrm{kHz}$ low pass) and amplified an additional $100 \times$ with a model 440 amplifier (Brownlee Precision). Signals were sampled at $25 \mathrm{kHz}$ with a Micro 1401 data acquisition unit and Spike2 software (Cambridge Electronic Design). We recorded one unit at a time (our data do not include any spike-sorted, simultaneously recorded units). Unit isolation was verified based on examination of overlaid spike waveforms and a plot of the principal components of the spike waveform calculated in Spike2 for consistency of spike shape, and evidence of a refractory period in a histogram of interspike intervals. Small, ionophoretic injections of the tracer $10 \mathrm{kDa}$ dextran amine conjugated to Alexa 488 or 568 (Invitrogen) were made to mark recording locations. 

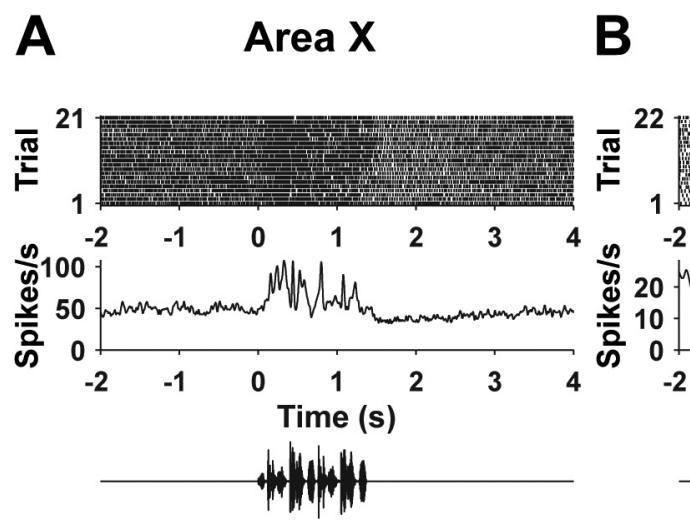

\section{Bird's Own Song (BOS)}
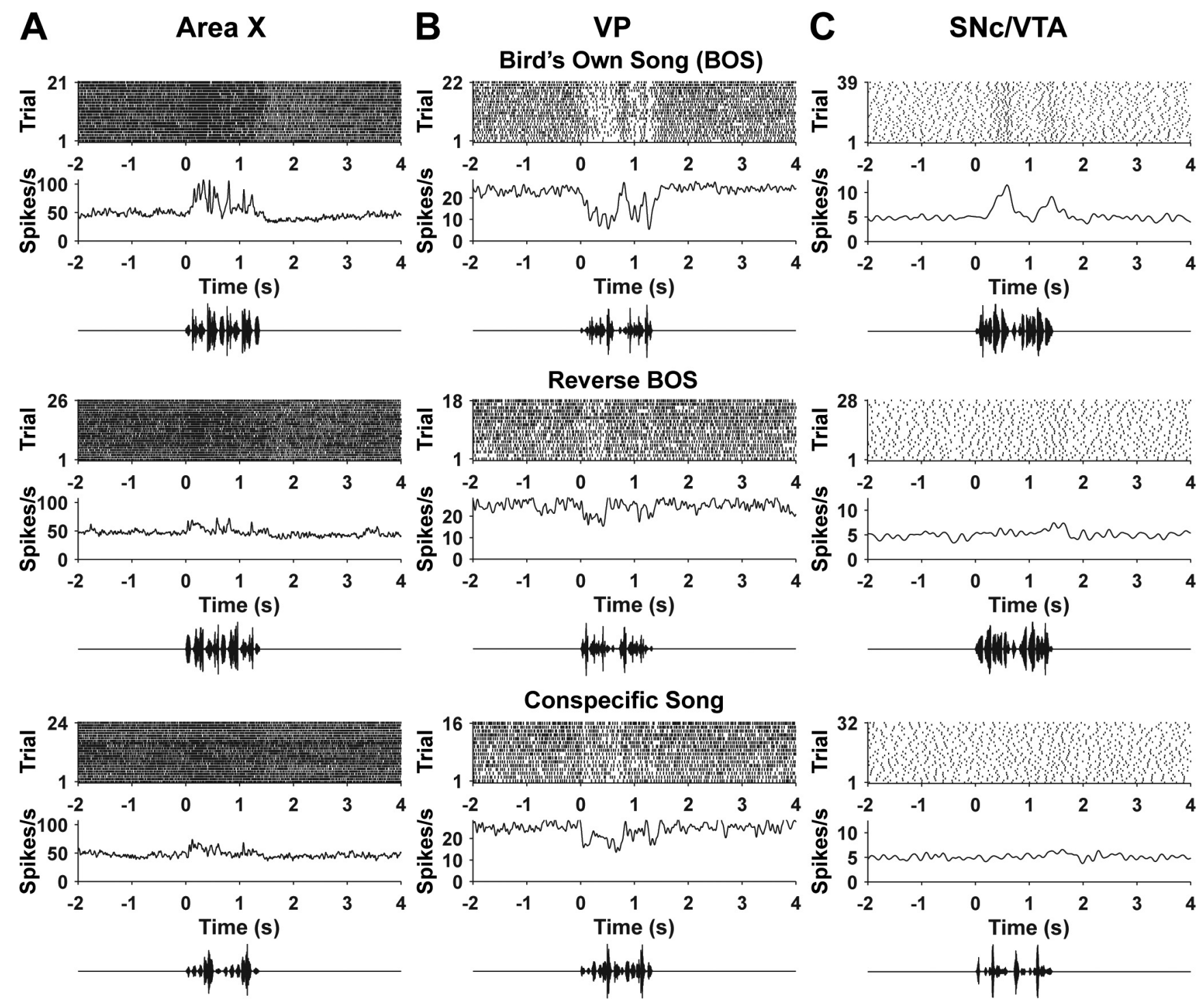

Figure 2. Auditory responses to BOS, reversed BOS, and conspecific song in example cells. $A$, Area X. B, VP. C, SNc/VTA dopaminergic neuron. For each brain region and stimulus, we show a raster plot indicating spike times on each trial, the average firing rate across trials (see Materials and Methods), and an oscillogram representing the auditory stimulus.

After some recordings in SNc/VTA, we attempted to juxtacellularly label the recorded neuron (Pinault, 1996). Neurobiotin (1.5\%) (Vector Laboratories) was included in the electrode solution for these experiments. Successful labeling occurred when increased action potential firing was entrained to $200 \mathrm{~ms}$ current steps (1-10 nA) delivered at $2.5 \mathrm{~Hz}$ for 2 min or longer.

Electrical stimulation of HVC. HVC was stimulated with a bipolar electrode placed $2.4 \mathrm{~mm}$ lateral to the bifurcation of the midsagittal sinus at a depth of $0.5 \mathrm{~mm}$. Single, monophasic pulses of $0.2 \mathrm{~ms}$ duration were delivered every $2 \mathrm{~s}$. Stimulation intensity $(0.2-1 \mathrm{~mA})$ was gradually increased until reliable responses were observed in an area $\mathrm{X}$ neuron and was kept at this intensity for subsequent recordings of VP or SNc/VTA neurons in the same animal. Further increasing the stimulation intensity did not induce a response in cases in which a VP or SNc/VTA neuron was not responsive to the initial intensity.

Drug injection in area $X$. Drugs were pressure injected into area $\mathrm{X}$ from glass pipettes with a tip diameter of $15-20 \mu \mathrm{m}$. The injection pipette entered the brain at an angle $10^{\circ}$ lateral to the midline. Pulses (10 psi, 50 ms duration) were delivered once every $2 \mathrm{~s}$ (Pressure System II; Toohey Company). Injection volumes ( $50-150 \mathrm{nl}$ ) were estimated by measuring the distance the meniscus in the back end of the pipette dropped after delivering several pressure pulses outside of the brain. This distance was converted to volume and divided by the number of pulses to derive the average volume ejected per pulse. GABA (250 mM) and glutamate (250 $\mathrm{mm}$ ) were dissolved in $0.9 \% \mathrm{NaCl}$. The AMPA receptor antagonist 6-nitro-7-sulfamoylbenzo $(f)$ quinoxaline-2,3-dione (NBQX) (1 mM) and NMDA receptor antagonist AP5 (5 mM) were injected together in a solution containing $0.9 \% \mathrm{NaCl}$ and $0.2 \%$ DMSO. Vehicle injections were $0.9 \% \mathrm{NaCl}$ and $0.2 \%$ DMSO. A solution of $0.5 \% 10 \mathrm{kDa}$ dextran amine conjugated to Alexa 568 was also injected to verify the injection location in area X.

The diameter of zebra finch area $\mathrm{X}$ is $\sim 1.2 \mathrm{~mm}$. Any spread of NBQX/ AP5 to striatal regions surrounding area $\mathrm{X}$ is not expected to influence auditory responses because neurons in these regions do not appear to respond to auditory stimuli in anesthetized zebra finches (our unpublished observations). Striatal regions outside of area $\mathrm{X}$ do not receive input from the song system. Effects of glutamate or GABA on striatal neurons outside of area X could potentially influence changes in dopaminergic neuron spontaneous firing. Spiny neurons in the striatum outside of area X, but not within area X, project to SNc/VTA (Gale et al., 2008; Person et al., 2008). These cells are thought to fire few spontaneous action potentials and it is not known which cell types they contact in $\mathrm{SNc} / \mathrm{VTA}$. Pallidal-like neurons in the striatum outside of area $\mathrm{X}$, like those within area X, appear to send axon collaterals to VP (Gale et al., 2008; Person et al., 2008), and spread of glutamate or GABA to these cells would presumably augment the effect of glutamate or GABA within area 
X. However, our recordings suggest minimal spread of drug outside of area X. Specifically, GABA injection inhibited spontaneous firing of area $X$ neurons 0.1 or $0.4 \mathrm{~mm}$ from the tip of the injection pipette, but no effects were observed $0.7 \mathrm{~mm}$ away, even with injection volumes exceeding those used for our experiments.

Histology. At the end of the experiment, birds were given a lethal dose of sodium pentobarbital via intramuscular injection and perfused transcardially with $0.9 \%$ saline followed by $4 \%$ paraformaldehyde. Brains were cryoprotected in $30 \%$ sucrose dissolved in $0.1 \mathrm{M}$ phosphate buffer (PB) and cut on a freezing microtome to $40 \mu \mathrm{m}$ sections.

Anterograde transport from area X to VP of tracer conjugated to one fluorophore was used to verify that VP recordings (marked by tracer conjugated to a different fluorophore) were made near axon terminals of area $\mathrm{X}$ neurons (Gale et al., 2008). Immunolabeling of tyrosine hydroxylase $(\mathrm{TH})$-positive cells was used to verify the location of tracer injections after SNc/VTA recordings and to identify juxtacellularly labeled cells as dopaminergic or nondopaminergic. As previously described (Gale and Perkel, 2006; Gale et al., 2008), tissue was incubated in rabbit anti-TH antibody (1:500; $\mathrm{AB} 152$; Millipore) in $\mathrm{PB}$ with $0.3 \%$ Triton overnight at $4^{\circ} \mathrm{C}$, and then in goat anti-rabbit secondary antibody conjugated to Alexa 647 (1:100) for $2 \mathrm{~h}$ at room temperature. To visualize juxtacellularly labeled cells, streptavidin conjugated to Alexa 488 or 568 (1:1000) was included with the secondary antibody after incubation with primary antibody against TH. Confocal images were captured with an Olympus FV-1000 confocal microscope (Olympus). Brightness and contrast of brightest point projections of $z$-series stacks were adjusted using Olympus Fluoview software.

Data analysis. Data were analyzed using MatLab (Mathworks). All VP and SNc/VTA neurons whose auditory responses were analyzed were recorded within $1 \mathrm{~h}$ of recording auditory responses in area X. Neurons were considered to have auditory responses if the firing rate during the stimulus was significantly higher than the firing rate during the $2 \mathrm{~s}$ preceding the stimulus for at least one of the six auditory stimuli (two-tailed, paired $t$ test with Bonferroni's correction, $\alpha=0.05 / 6)$. Singletrial auditory responses were quantified by tak-

ing the difference between the firing rate during the auditory stimulus and the firing rate during a $2 \mathrm{~s}$ baseline preceding the stimulus. The mean response strength is the average response across all trials of a given stimulus. To quantify the separation of the distributions of responses to BOS and each of the non-BOS stimuli, we used the discriminability index, $d^{\prime}$, which was calculated as the difference between the mean response to BOS and a non-BOS stimulus divided by the square root of the average of the variance of the responses to those stimuli as follows: $d^{\prime}=$ (mean $R_{\mathrm{BOS}}-$ mean $\left.R_{\text {non-Bos }}\right) /$ squareroot [ $\left.\left(\operatorname{var} R_{\mathrm{BOS}}+\operatorname{var} R_{\text {non-Bos }}\right) / 2\right]$, where $R$ is a population of single-trial responses (Green and Swets, 1966; Solis and Doupe, 1997; Theunissen and Doupe, 1998; Person and Perkel, 2007). When responses are positive (all area X and SNc/VTA neurons), $d^{\prime}$ is positive if the response to BOS is greater than the response to a non-BOS stimulus or negative if the response to the non-BOS stimulus is greater than the response to BOS. The opposite would be true for VP neurons,
Area X B Area X

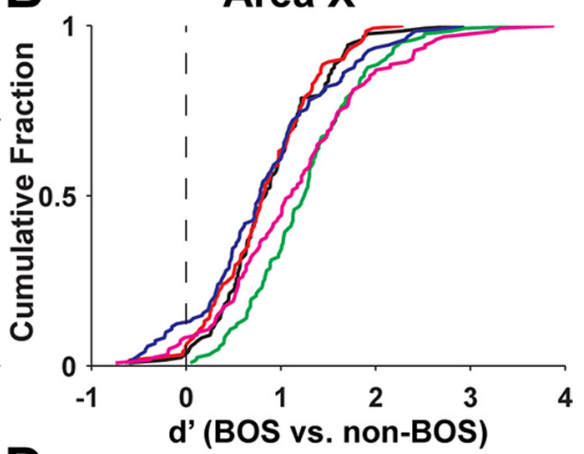

D VP
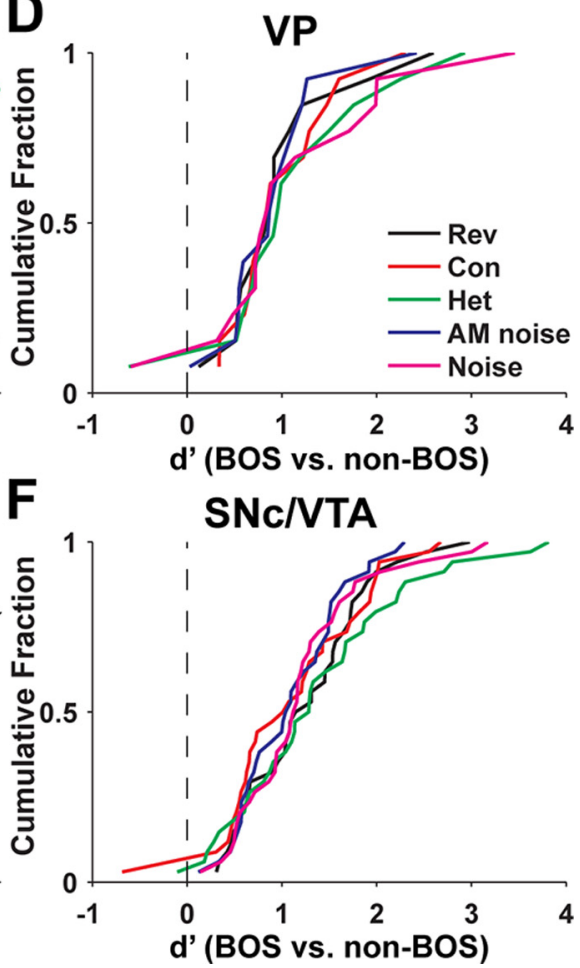

Figure 3. Response strength and selectivity of all area X, VP, and SNc/VTA dopaminergic neurons recorded. $A$, For each area X neuron ( $n=122$ cells, 67 birds), mean response to BOS ( $y$-axis) compared with the mean response to each of the five non-BOS stimuli ( $x$-axis), which include reverse BOS (Rev; black circles), conspecific song (Con; red circles), heterospecific song (Het; green , amplitude-modulated noise (blue circles), and unmodulated noise (magenta circles), as indicated in $\boldsymbol{C}$. Each cell contribtes a row of five circles with the same $y$-axis value. The dashed line has slope unity. $\boldsymbol{B}$, Cumulative probability distribution of $d^{\prime}$ values (see Materials and Methods) for area $X$ neurons comparing responses to $B O S$ with responses to each of the non-BOS stimuli, Values of $d^{\prime}$ for VP neurons were multiplied by -1 (see Materials and Methods). $\boldsymbol{E}$, Same as $\boldsymbol{A}$ for SNc/VTA dopaminergic neurons ( $n=34$ cells, 18 birds). $\boldsymbol{F}$, Same as $\boldsymbol{B}$ for SNc/VTA dopaminergic neurons.

which were always inhibited by BOS; however, we multiplied $d^{\prime}$ values for VP neurons by -1 for direct comparisons to $d^{\prime}$ values in area $\mathrm{X}$ and SNc/VTA (see Fig. 3D).

Mean firing rate functions (see Figs. 2, 7A) were generated by convolving the spike times for each trial with a Guassian filter and then averaging across trials (Baker and Gerstein, 2001). The width at half-height of the Gaussian filter was $10 \mathrm{~ms}$ for area X neurons, $20 \mathrm{~ms}$ for VP, and $50 \mathrm{~ms}$ for SNc/VTA dopaminergic neurons. The sampling interval for the rate function was $1 \mathrm{~ms}$.

Auditory response latencies were calculated from mean firing rate functions as follows. The mean and SD of the firing rate during the $2 \mathrm{~s}$ baseline period before stimulus onset were determined. A threshold firing rate was set as the baseline mean \pm 3 SDs. Response onset was defined as the first point closest to and preceding threshold crossing to deviate from the mean firing rate by $>10 \%$ in the same direction. Latencies calculated this way matched well our subjective sense of when the re- 

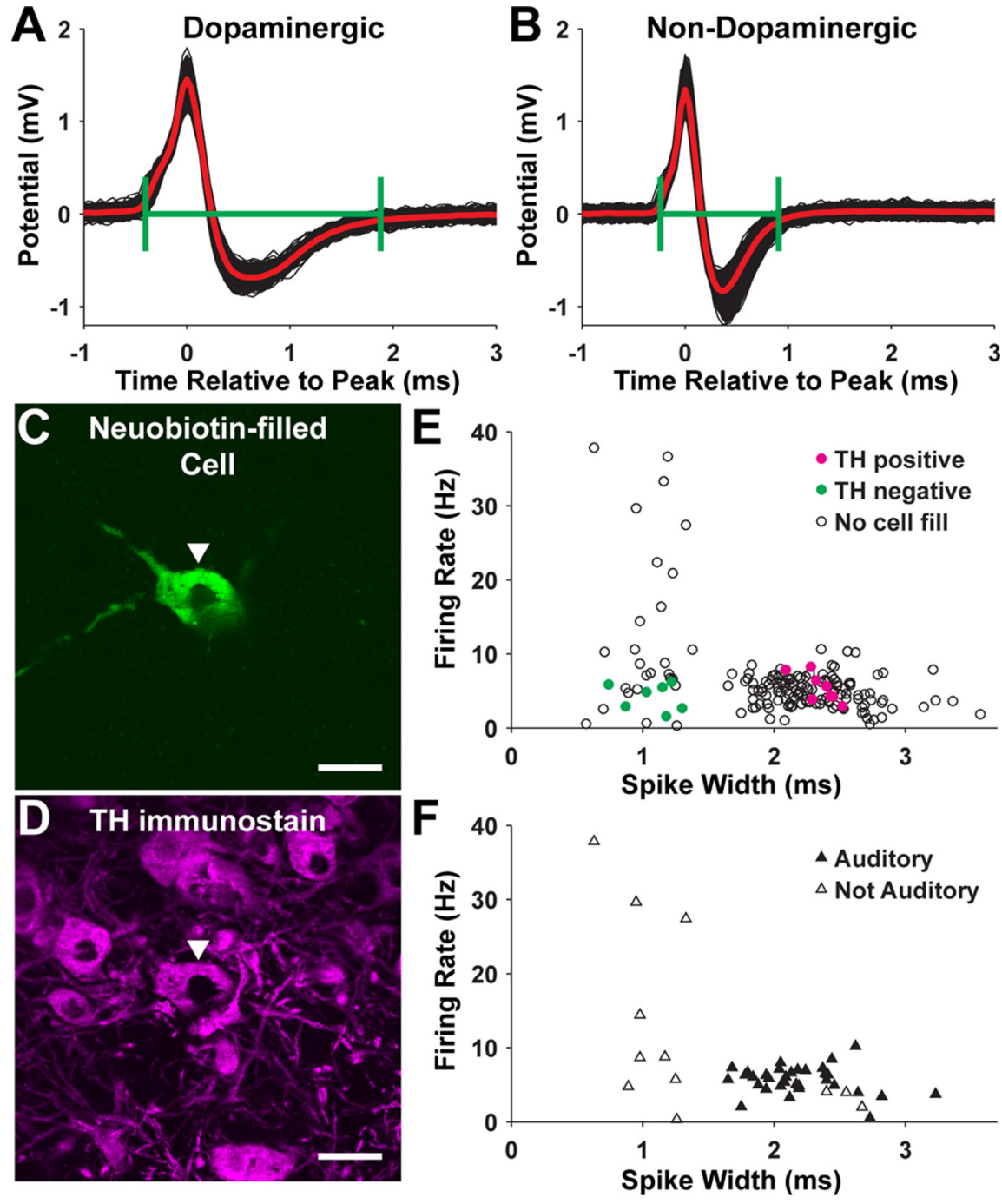

Figure 4. Identification of dopaminergic neurons in the SNc/VTA by spike waveform and juxtacellular labeling. $\boldsymbol{A}, 0$ verlaid waveforms of spikes from a dopaminergic neuron (thin black lines). The thick, red line is the average spike waveform. The green brackets indicate the spike duration as defined in Materials and Methods. $\boldsymbol{B}$, Same as $\boldsymbol{A}$ for a nondopaminergic neuron. $\boldsymbol{C}$, Image of a juxtacellularly labeled cell. $\boldsymbol{D}$, The cell in $\boldsymbol{C}$ is TH immunopositive. Scale bars: $\boldsymbol{C}, \boldsymbol{D}, 20 \mu \mathrm{m}$. $\boldsymbol{E}$, Spontaneous firing rate and spike duration of all cells recorded in SNc/VTA. Cells that were juxtacellularly labeled and shown to be TH immunopositive are indicated with filled, magenta circles. Juxtacellularly labeled cells that were TH negative are shown with filled, green circles. Cells that were not labeled are shown with open circles. $\boldsymbol{F}$, Similar to $\boldsymbol{E}$ except showing the subset of cells whose auditory responses were tested. Cells that had auditory responses are indicated by filled triangles, and cells that were not responsive are shown with open triangles.

sponse began. Mean firing rate functions were averaged across cells from birds with different BOS durations (see Fig. $5 A$ ) by resampling rate functions such that the firing rate during BOS playback and equal durations preceding and after BOS playback were each represented by 1400 points, corresponding to the median BOS stimulus duration of $\sim 1400 \mathrm{~ms}$.

To calculate spike duration, spike waveforms were aligned by their initial, positive-going peak and then averaged. Spike duration, calculated from this average waveform, was defined as the duration from the point preceding the initial, positive-going peak at which the potential reached $10 \%$ of the amplitude of this peak to the point at which the potential returned to $10 \%$ of the amplitude of negative-going peak after that peak (see Fig. 4A,B) (Gale and Perkel, 2006). There was no correlation between spike duration and spike amplitude (the latter was calculated as the difference in potential between the positive- and negative-going peaks; $\left.r^{2}=0.0034\right)$.

For HVC stimulation experiments, peristimulus time histograms (PSTHs) were made with $1 \mathrm{~ms}$ bin widths for area $\mathrm{X}$ neurons, $2 \mathrm{~ms}$ for $\mathrm{VP}$, and $5 \mathrm{~ms}$ for SNc/VTA (no smoothing). A threshold was set as the mean \pm 3 SDs of the bins preceding stimulation by $1 \mathrm{~s}$ or less. Neurons were considered responsive if two or more consecutive bins crossed threshold. Response onset was the time of the center of the first of these threshold crossing bins and response offset was the time of the first bin after the onset that was below threshold. Peak response was the maximum PSTH bin.

To quantify the effects of NBQX/AP5 or vehicle injection in area $\mathrm{X}$ on auditory responses in SNc/VTA dopaminergic neurons (see Fig. 7 ), we calculated the mean response for all (1020) BOS trials preceding drug injection (baseline), the mean response for an equal number of BOS trials after NBQX/AP5 injection, and the mean response for the same number of trials closest to the end of the recording for a given cell (wash). To quantify the effects of glutamate and GABA injection in area $\mathrm{X}$ on the firing rate of SNc/VTA dopaminergic neurons (see Fig. 8), we plotted the firing rate versus time in $5 \mathrm{~s}$ bins. We calculated the firing rate during the $50 \mathrm{~s}$ period preceding glutamate or GABA injection (baseline), the maximum change in firing rate after glutamate or GABA injection (maximum or minimum $5 \mathrm{~s}$ bin), and the firing rate during the last $50 \mathrm{~s}$ of the recording (wash).

Values are expressed in Results as mean \pm SD. Statistical tests were performed in GraphPad Prism software (GraphPad) or MatLab with $\alpha=0.05$. $t$ tests were used to compare two groups, and ANOVAs with Tukey's post hoc multiple-comparison test were used to compare three or more groups. The Kolmogorov-Smirnov test was used to compare distributions of $d^{\prime}$ values.

\section{Results}

Auditory responses of area $\mathrm{X}, \mathrm{VP}$, and SNc/VTA neurons

We recorded responses of area $\mathrm{X}, \mathrm{VP}$, and $\mathrm{SNc} / \mathrm{VTA}$ neurons to auditory stimuli including BOS. If area $\mathrm{X}$ output drives auditory responses in VP neurons, and these same VP neurons project to $\mathrm{SNc} /$ VTA, we predicted that, like area $\mathrm{X}$ neurons, VP and SNc/VTA neurons would respond preferentially to BOS. Furthermore, auditory responses in area $\mathrm{X}$ should precede those in VP, and auditory responses in VP should precede those in SNc/VTA.

Although auditory responses of area $\mathrm{X}$ neurons in adult zebra finches were described previously (Doupe, 1997; Solis and Doupe, 2000; Person and Perkel, 2007), we recorded from area X neurons so that we could directly compare the selectivity and latency of auditory responses in area X, VP, and SNc/VTA under identical conditions. Similar to previous descriptions, area $\mathrm{X}$ neurons increased their firing rate in response to BOS $(n=122)$. Area $\mathrm{X}$ neurons often responded to other auditory stimuli as well, but responses to $\mathrm{BOS}$ were almost always stronger than responses to non-BOS stimuli (Figs. 2A, 3A). The mean response to BOS was significantly greater than the mean response to each nonBOS stimulus $\left(F_{(5,726)}=110.5 ; p<0.0001\right)$. We quantified this "BOS selectivity" in each area X neuron for comparison to VP and SNc/VTA neurons using the discriminability index, $d^{\prime}$ (see Materials and Methods) (Fig. 3B). 
There are several cell types in area X, including all four cell types found in the mammalian striatum as well as a cell type with physiological and morphological properties similar to mammalian pallidal neurons (Farries and Perkel, 2002). These pallidallike neurons - the only cells that project out of area X-make GABAergic terminals in the medial portion of the dorsolateral nucleus of the thalamus (DLM) and branching collaterals that terminate in VP (Luo and Perkel, 1999; Farries et al., 2005; Gale et al., 2008). The fast-firing neurons we recorded in area $\mathrm{X}$ (spontaneous firing rate of $55 \pm 14$ spikes/s; range, 25-94 spikes/s) are thought to represent exclusively pallidal-like neurons in area $\mathrm{X}$ based on their known intrinsic properties (Farries and Perkel, 2002). Indeed, at least $67 \%$ of area $X$ neurons with firing rates $>25$ spikes/s are projection neurons (identified by antidromic stimulation) (Leblois et al., 2009). Furthermore, neither the mean response to BOS nor the selectivity for BOS versus reversed BOS $\left(d^{\prime}\right)$ differed significantly between the area $\mathrm{X}$ neurons we recorded and identified area $\mathrm{X}$ projection neurons recorded at their terminals in DLM (Person and Perkel, 2007) $(t$ tests, $p>$ $0.5)$. Thus, the auditory responses we recorded in area $X$ are representative of the input received from area X by VP neurons.

\section{VP neurons are inhibited by auditory stimulation and respond preferentially to $\mathrm{BOS}$}

Thirteen of 28 VP neurons recorded had auditory responses. The spontaneous firing rate of the responsive VP neurons $(23 \pm 11$ spikes/s; range, 10-45 spikes/s) did not significantly differ from the spontaneous firing rate of nonresponsive VP neurons $(27 \pm 9$ spikes/s; range, $11-46$ spikes/s; $t$ test, $p>0.3)$. All 13 responsive $\mathrm{VP}$ neurons were inhibited by BOS playback, and responses to BOS were almost always stronger than responses to non-BOS stimuli (Figs. 2 B, $3 C)$. The mean response to BOS was significantly stronger than the mean response to each non-BOS stimulus $\left(F_{(5,72)}=8.34 ; p<\right.$ $0.0001)$. The distributions of $d^{\prime}$ values comparing responses to BOS and non-BOS stimuli were not significantly different for area $\mathrm{X}$ and VP neurons (Fig. 3 $B, D$ ) (Kolmogorov-Smirnov test, $p>0.3$ for each of five comparisons).

\section{SNc/VTA dopaminergic neurons show increased firing in} response to auditory stimulation and respond preferentially to BOS

The zebra finch SNc/VTA contains both dopaminergic and nondopaminergic neurons, which can be distinguished by their intracellularly or extracellularly recorded spike shapes in brain slices (Gale and Perkel, 2006). We made extracellular recordings of spontaneous activity from 165 neurons in the SNc/VTA in vivo. As expected, we found evidence for two populations of cells. One group had relatively long-duration spikes and spontaneous firing rates between 0.5 and 10 spikes/s; the other had shorterduration spikes and a larger range of spontaneous firing rates (0.33-38 spikes/s) (Fig. 4E). We juxtacellularly labeled 15 of these cells (Fig. 4C,D). All eight of the cells with long-duration spikes $(>1.6 \mathrm{~ms}$ ) were $\mathrm{TH}$ immunopositive, and all seven of the cells with short-duration spikes $(<1.4 \mathrm{~ms})$ were $\mathrm{TH}$ negative (Fig. $4 E$ ). These results are qualitatively similar to our findings in brain slices (Gale and Perkel, 2006). We refer to SNc/VTA cells with long-duration spikes as dopaminergic and cells with shortduration spikes as nondopaminergic.

Nearly all dopaminergic neurons tested exhibited auditory responses ( $n=34$ of 37 ) (Fig. $4 F)$. Dopaminergic neurons increased their firing rate in response to BOS playback, and responses to BOS were almost always stronger than responses to non-BOS stimuli (Figs. $2 C, 3 E$ ). The mean response to BOS was significantly larger than the mean response to each non-BOS stimulus $\left(F_{(5,198)}=32.47 ; p<0.0001\right)$. The distributions of $d^{\prime}$ values comparing responses to BOS and non-BOS stimuli for dopaminergic neurons were not significantly different from those for area $\mathrm{X}$ and VP neurons (Fig. 3B,D,F) (Kolmogorov-Smirnov tests, $p>0.05$ ), except for $d^{\prime}$ distributions for BOS versus reverse BOS when comparing area X and dopaminergic neurons $(p<0.05)$. Similarly, mean $d^{\prime}$ values were not significantly different between area $\mathrm{X}, \mathrm{VP}$, and dopaminergic neurons except that dopaminergic neurons were more selective for BOS versus reversed BOS than area $\mathrm{X}$ neurons (ANOVA with Tukey's post hoc multiple-comparison tests). Hence, auditory responses in VP and dopaminergic neurons were equivalent or greater in their BOS selectivity compared with auditory responses in song system nucleus area X.

The increased firing rate of dopaminergic neurons in response to BOS could be driven by auditory input to SNc/VTA that directly either excites or disinhibits dopaminergic neurons. Alternatively, nondopaminergic neurons in the zebra finch SNc/VTA, if they receive auditory input and make synaptic contact with dopaminergic neurons, could underlie auditory responses in dopaminergic neurons. We did not observe auditory responses in nondopaminergic SNc/VTA neurons $(n=9)$ (Fig. $4 F)$. Hence, BOS-selective auditory input to SNc/VTA most likely influences dopaminergic neurons directly.

The average response to BOS of all area $\mathrm{X}, \mathrm{VP}$, and dopaminergic neurons recorded is shown in Figure $5 A$. In summary, the

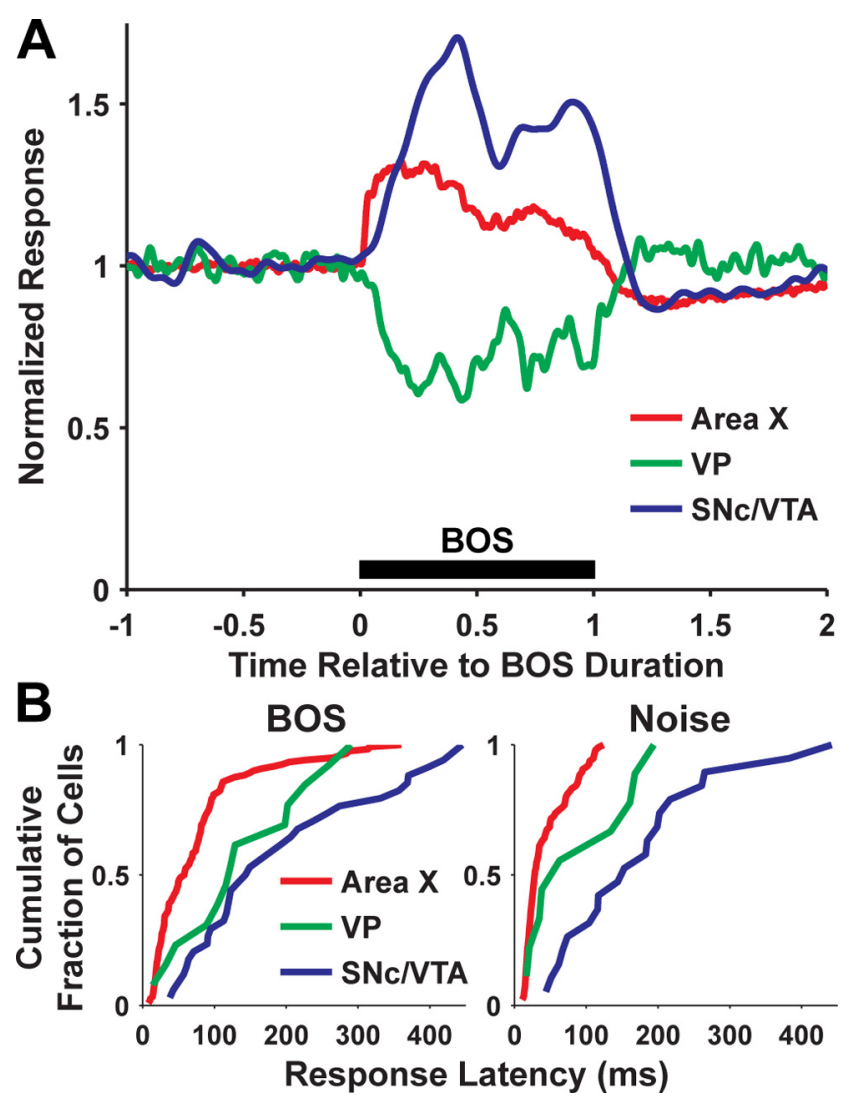

Figure 5. Population response to BOS and response latency of area $X, V P$, and SNc/VTA dopaminergic neurons. $\boldsymbol{A}$, Average firing rate (normalized to baseline) of area X (red), VP (green), and SNc/VTA dopaminergic neurons (blue) during BOS playback. Time is normalized to the duration of BOS (see Materials and Methods). $\boldsymbol{B}$, Cumulative probability distribution of response latencies to BOS (left) for area X $(n=122), \mathrm{VP}(n=13)$, and SNc/VTA dopaminergic neurons $(n=34)$, or response latencies to noise (right; $n=97$, area X; $n=9, \mathrm{VP} ; n=19$, SNc/VTA). 


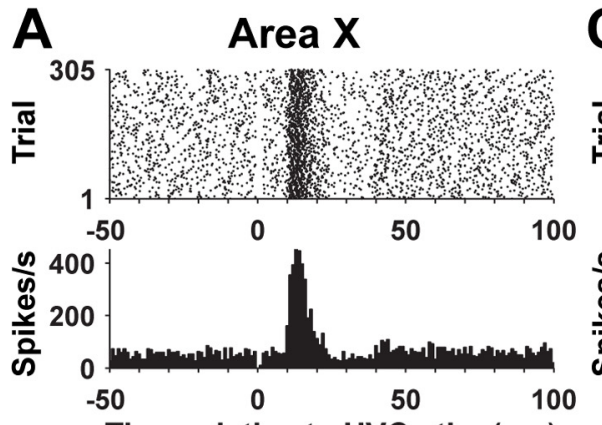

Time relative to HVC stim (ms)
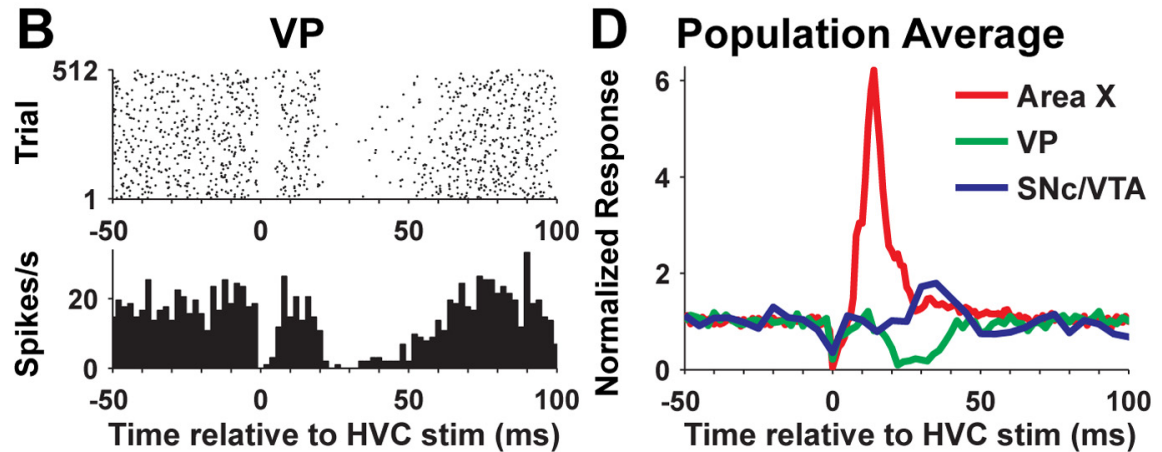

Figure 6. Response of area X, VP, and SNc/VTA dopaminergic neurons to electrical stimulation (stim) in HVC. $\boldsymbol{A}$, Raster plot and PSTH for an area X neuron. Single-pulse electrical stimulation of HVC occurred at time 0 . Missing spikes near time 0 are attributable to the stimulation artifact, which obscures any spikes that occur near that time. $\boldsymbol{B}$, Same as $\boldsymbol{A}$ for a VP neuron from a different bird. C, Same as $\boldsymbol{A}$ and $\boldsymbol{B}$ for a dopaminergic neuron from a different bird. $\boldsymbol{D}$, Average PSTH for all area X ( $n=31$ cells, 18 birds), VP ( $n=10$ cells, 5 birds), and SNc/VTA dopaminergic neurons ( $n=2$ cells, 2 birds).

sign of these responses (increase or decrease in firing rate) and similar BOS selectivity are consistent with a model in which increased firing of area X projection neurons inhibits spontaneous firing of VP neurons and thereby disinhibits dopaminergic neurons (Fig. 1C).

Response latencies to auditory stimuli and to electrical stimulation of area $\mathrm{X}$ afferents

If area X inhibits VP neurons and inhibition of VP neurons then disinhibits dopaminergic neurons, auditory responses of VP neurons should occur after auditory responses of area $\mathrm{X}$ neurons and before auditory responses of dopaminergic neurons. Our results are consistent with this prediction. Responses to BOS tended to occur with shorter latencies in area X neurons $(76 \pm 71 \mathrm{~ms})$ than VP neurons ( $141 \pm 88 \mathrm{~ms}$ ), and shorter latencies in VP neurons than dopaminergic neurons $(193 \pm 128 \mathrm{~ms}$ ) (Fig. 5B, left). Response latencies to BOS were significantly shorter in area $\mathrm{X}$ than in VP and dopaminergic neurons $(p<0.05)$, but were not significantly different for VP and dopaminergic neurons $(p>$ 0.05; ANOVA with Tukey's post hoc multiple-comparison tests, $\left.F_{(2,166)}=25.46, p<0.0001\right)$. Because amplitude modulation at the onset of BOS is variable between birds, we also calculated response latencies to noise in the subset of neurons that responded to noise (area X, $n=97$ of $122 ; \mathrm{VP}, n=9$ of 13 ; SNcl VTA, $n=19$ of 34$)$. Response latencies to noise were significantly shorter in area X neurons ( $43 \pm 31 \mathrm{~ms}$ ) than VP neurons ( $92 \pm 71$ $\mathrm{ms} ; p<0.05)$ and significantly shorter in VP neurons than dopaminergic neurons $(172 \pm 109 \mathrm{~ms} ; p<0.001)$ (Fig. $5 B$, right) $\left(F_{(2,122)}=47.41 ; p<0.0001\right)$.

Auditory response latencies reflect intrinsic properties of different neuron types and temporal integration of auditory-driven synaptic input in addition to conduction delays between brain regions. To further examine response delays between area $\mathrm{X}$ and VP, and between $\mathrm{VP}$ and SNc/VTA, we took advantage of the monosynaptic, glutamatergic projection to area $\mathrm{X}$ pallidal-like neurons from HVC (Fig. 1) (Farries et al., 2005). We used single-pulse electrical stimulation of HVC to drive very large and brief excitatory responses in area X pallidal-like neurons. Responses of area $\mathrm{X}$ pallidal-like neurons to HVC stimulation $(n=31)$ (Fig. 6A,D) had latencies of $9 \pm 2 \mathrm{~ms}$ (range, 5-15 ms), durations of $15 \pm 7 \mathrm{~ms}$ (range, 3-39 ms), and peak firing rates of $459 \pm 110$ spikes/s (range, 208-710 spikes/s). Ten of $16 \mathrm{VP}$ neurons responded to HVC stimulation (Fig. $6 B, D$ ). All 10 of these neurons were inhibited by HVC stimulation, with response latencies of $20 \pm 4 \mathrm{~ms}$ (range, $14-28 \mathrm{~ms}$ ), response durations of $24 \pm 10 \mathrm{~ms}$ (range, $12-40$ $\mathrm{ms}$ ), and minimum firing rates of $0.5 \pm$ $1.3 \mathrm{spikes} / \mathrm{s}$ (range, $0-4$ spikes/s; 0 in 8 of 10 cells). The "floor" of 0 spikes/s for inhibition of VP neurons, in contrast to the very large increase in firing rate elicited in area $\mathrm{X}$ neurons, leaves just a $\sim 20 \mathrm{~ms}$ "pause" in inhibition as the predicted stimulus for dopaminergic neurons after HVC stimulation. Nonetheless, we observed responses to HVC stimulation in 2 (of 15) dopaminergic neurons (Fig. 6C,D). Both of these cells were excited after HVC stimulation with latencies of $30 \mathrm{~ms}$. Peak firing rates were 12.2 spikes/s (from 7.2 spikes/s baseline firing rate) and 6.4 spikes/s (from 3.0 spikes/s baseline firing rate). In summary, area $\mathrm{X}$ pallidal-like neurons respond to stimulation of their monosynaptic input from HVC with a latency just under 10 ms. Similarly, response delays between area X pallidal-like neurons and VP, and between VP and dopaminergic neurons, are $\sim 10 \mathrm{~ms}$. These data are consistent with monosynaptic connections from area $\mathrm{X}$ to VP and from VP to dopaminergic neurons.

Auditory responses in area $\mathrm{X}$ are necessary for auditory responses in dopaminergic neurons

To test directly the role of area $\mathrm{X}$ in generating auditory responses in dopaminergic neurons, we recorded auditory responses in dopaminergic neurons and then blocked auditory responses in area $\mathrm{X}$ with the ionotropic glutamate receptor antagonists NBQX and AP5. NBQX/AP5 injection in area X substantially reduced auditory responses of dopaminergic neurons $(n=5$; $77 \pm 11 \%$ reduction; range, $66-89 \%$ reduction) (Fig. $7 A, B$ ). Moderate recovery of responses to $\mathrm{BOS}$ was recorded in three of five dopaminergic neurons before the end of recording (Fig. $7 B$ ). In contrast, vehicle injection in area $\mathrm{X}$ had no effect on auditory responses in dopaminergic neurons $(n=5)$ (Fig. $7 C)$. Change in baseline firing rate would complicate interpretation of any change (or lack thereof) in auditory responses. Importantly, NBQX/AP5 or vehicle injection in area X had no effect on the baseline firing rate of dopaminergic neurons (Fig. 7D). Thus, auditory responses in area $\mathrm{X}$ play a major role in generating auditory responses in SNc/VTA dopaminergic neurons. 
Change in area $\mathrm{X}$ output is sufficient to modulate the firing rate of dopaminergic neurons bidirectionally What is the mechanism by which area $\mathrm{X}$ influences auditory responses in dopaminergic neurons? One possibility is that area $\mathrm{X}$ activation, by inhibiting $\mathrm{VP}$, reduces tonic inhibition of dopaminergic neurons and thereby allows intrinsic mechanisms in these cells and/or background (nonauditory driven) excitatory synaptic input to drive increased action potential firing. In this case, auditory responses in area $\mathrm{X}$ are sufficient to drive auditory responses in dopaminergic neurons. An alternative possibility is that this same disinhibition of dopaminergic neurons allows auditory-driven excitatory input, from an unknown pathway, to drive auditory responses in dopaminergic neurons. In this case, disinhibition from area $\mathrm{X}$ (via VP) acts as a gate. To ask whether activation of area $\mathrm{X}$ can modulate the firing rate of dopaminergic neurons in the absence of any auditory input, we injected glutamate into area X. Glutamate injection in area $\mathrm{X}$ caused a complex response in area X pallidal-like neurons. A brief excitation was followed by a cessation of firing and then a prolonged increase in firing rate that slowly returned to baseline $(n=$ 5) (Fig. $8 A, B$ ). The transient inhibition of area $\mathrm{X}$ neurons after glutamate injection could be caused by depolarization block or release of inhibitory neurotransmitters from other area X cell types. Similar responses were observed in SNc/VTA dopaminergic neurons after glutamate injection in area $\mathrm{X}(n=8)$ (Fig. $8 C, D)$. The peak firing rate (measured in $5 \mathrm{~s}$ bins) of dopaminergic neurons after glutamate injection in area $\mathrm{X}$ was on average double the baseline firing rate $(96 \pm 37 \%$ increase; range, $47-163 \%$ increase). Hence, area $\mathrm{X}$ activation, in the absence of any auditory stimuli, is sufficient to increase the firing rate of dopaminergic neurons by a magnitude comparable with responses to BOS playback (Figs. $3 E, 5 A$ ). Inactivation of area $\mathrm{X}$ pallidal-like neurons via GABA injection in area $\mathrm{X}$ (Fig. $8 E, F$ ) inhibited spontaneous firing of dopaminergic neurons $(n=5$; $79 \pm 22 \%$ inhibition; range, $49-100 \%$ inhibition) (Fig. 8G, H). Thus, area $\mathrm{X}$ can bidirectionally modulate the firing rate of $\mathrm{SNc} /$ VTA dopaminergic neurons.

\section{Discussion}

Our results demonstrate activation of dopaminergic neurons in songbirds by area $\mathrm{X}$, a basal ganglia nucleus required for song learning. Auditory responses of dopaminergic neurons are selective for BOS and require area X. Modulation of area X output is sufficient to drive changes in the firing rate of dopaminergic neurons. The only known anatomical pathway from area $\mathrm{X}$ to dopaminergic neurons involves a collateral projection of area $\mathrm{X}$ pallidal-like neurons to VP, which in turn projects to SNc/VTA. VP neurons are spontaneously active and inhibited preferentially
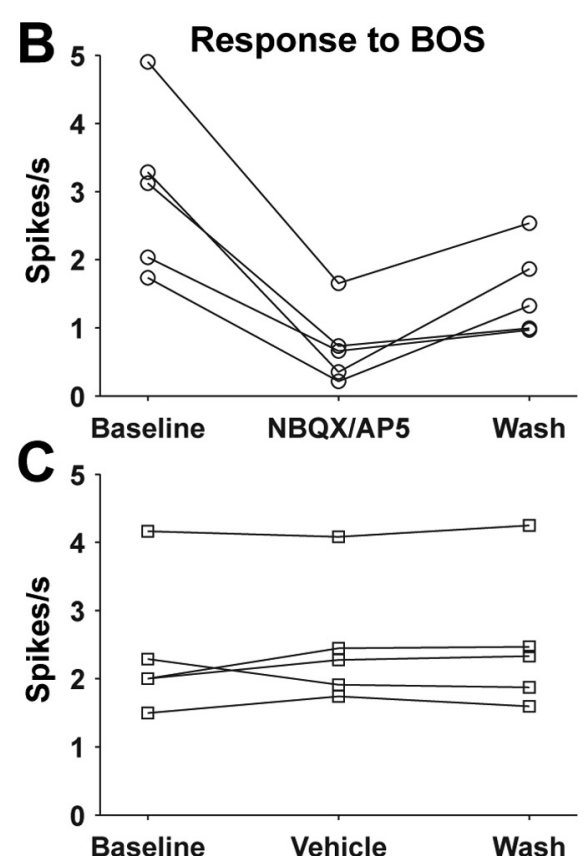

Wash

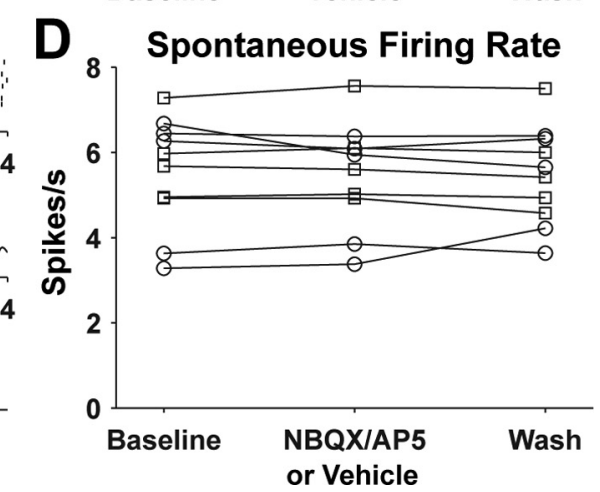

Figure 7. Effects of NBQX/AP5 injection in area X on auditory responses of SNc/VTA dopaminergic neurons. $\boldsymbol{A}$, Response of a dopaminergic neuron to BOS before NBQX/AP5 injection in area X (top), after NBQX/AP5 injection in area X (middle), and during the ast BOS trials of the recording (bottom). $\boldsymbol{B}$, Response of five dopaminergic neurons (from 4 birds) to BOS before and afte injection in area X. D, Spontaneous firing rate of the dopaminergic neurons shown in $\boldsymbol{B}$ and $\boldsymbol{C}$ before and after NBQX/AP5 (circles) or vehicle (squares) injection in area $X$.

by $\mathrm{BOS}$, suggesting that area $\mathrm{X}$ disinhibits dopaminergic neurons by inhibiting VP (Fig. 1C).

Previously, activation of dopaminergic neurons has been described in mammals in response to rewards (food, water) or reward-predicting cues, and more generally by novel, surprising, or otherwise arousing events (Schultz, 1998; Horvitz, 2000). These responses occur at short latency (typically $<100 \mathrm{~ms}$ ) and are thought to be driven by excitatory synaptic input, although the anatomical sources of this input are still being resolved (Dommett et al., 2005; Pan and Hyland, 2005). The nature of sensory input received by dopaminergic neurons and the ability of these neurons to discriminate complex sensory cues has been questioned (Redgrave et al., 2008). Phasic excitation in response to salient nonreward events is brief and often followed by inhibition (Schultz, 1998: Horvitz et al., 2007). Responses to rewardrelated stimuli are longer and under some conditions the later portion of responses best discriminates conditioned stimuli (Fiorillo et al., 2008). This may reflect a delayed gating mechanism that inhibits nonreward responses and/or disinhibits rewardrelated responses to varying degrees. The mammalian SNc and 


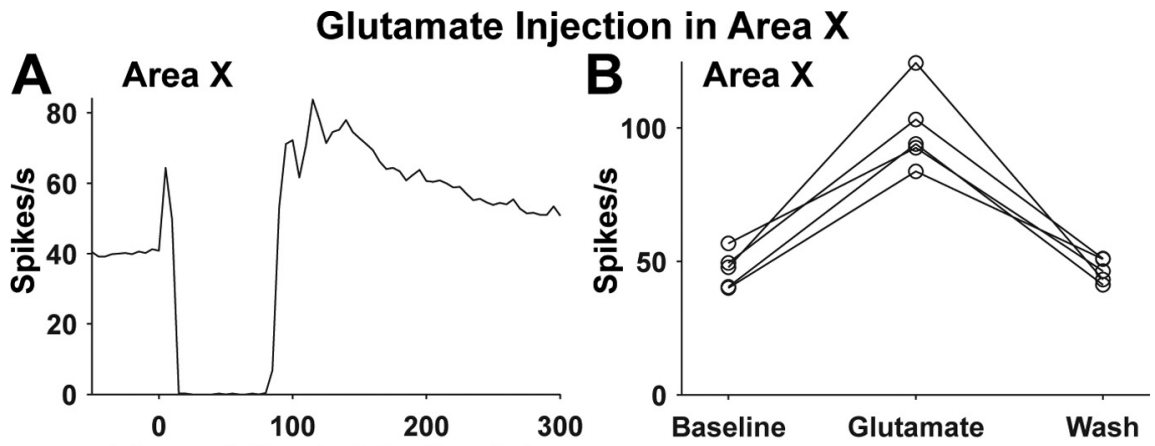

Time relative to injection (s)

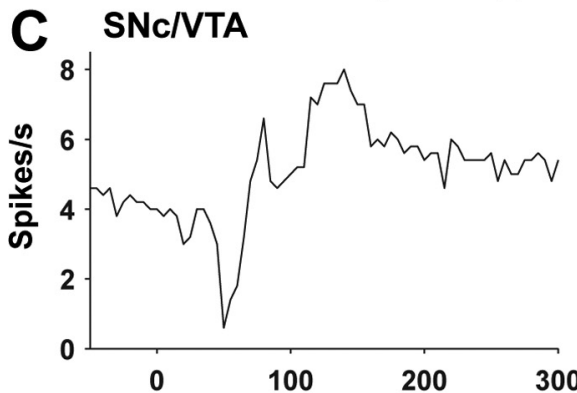

Time relative to injection (s)

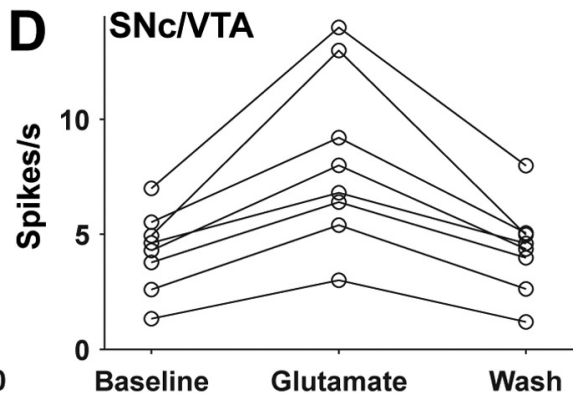

GABA Injection in Area $X$
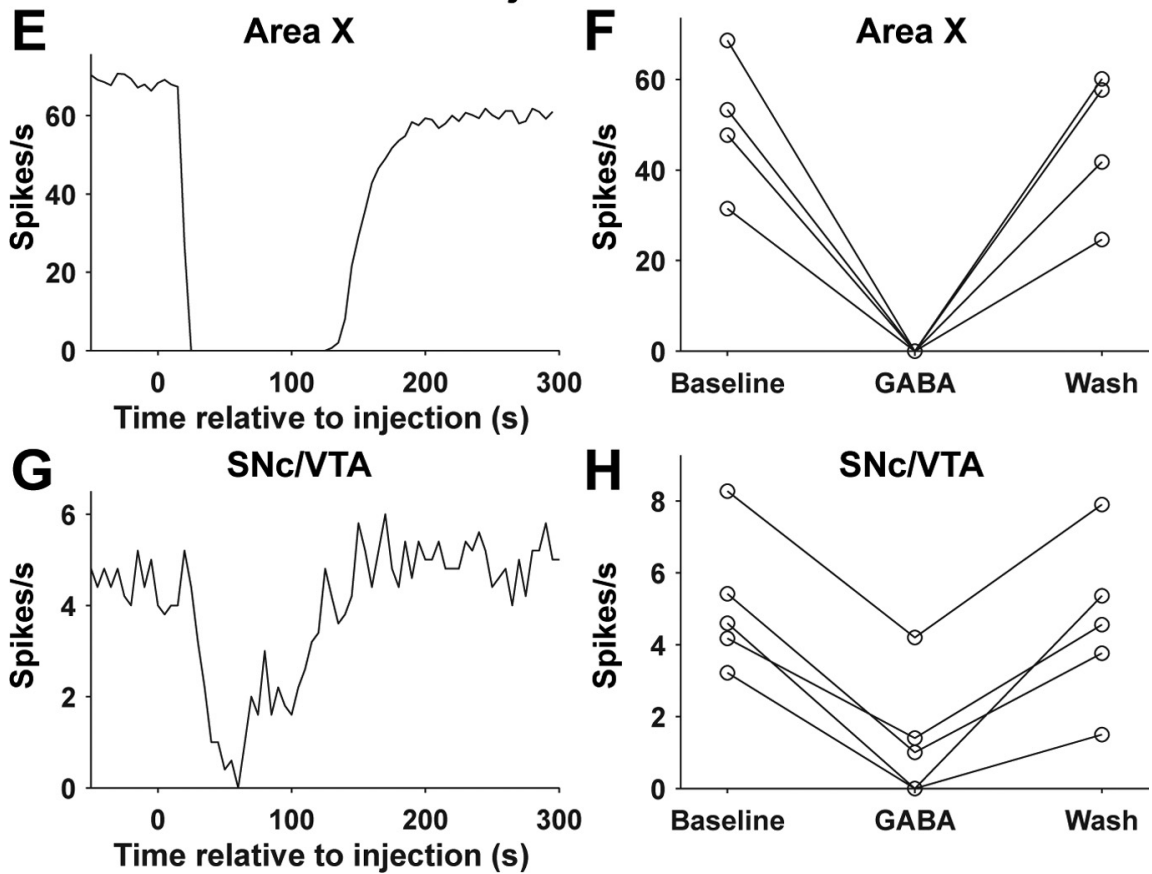

Figure 8. Effects of glutamate and GABA injection in area $X$ on the spontaneous firing rate of area $X$ and SNc/VTA dopaminergic neurons. $A$, Response of an area $X$ neuron to glutamate injection in area $X$ at time $0 . B$, Spontaneous firing rate of five area $X$ neurons (from 3 birds) before and after glutamate injection in area $X$ (see Materials and Methods). $C$, Response of a dopaminergic neuron to glutamate injection in area $X$ at time 0 . The cells shown in $A$ and $C$ were not recorded simultaneously. $\boldsymbol{D}$, Spontaneous firing rate of eight dopaminergic neurons (from 4 birds) before and after glutamate injection in area X. $\boldsymbol{E}-\boldsymbol{H}$, Same as $\boldsymbol{A}-\boldsymbol{D}$ but for GABA injection in area $\mathrm{X}$. Area $\mathrm{X}, n=4$ cells, 2 birds $(\boldsymbol{F})$. SNc/VTA, $n=5$ cells, 5 birds $(\boldsymbol{H})$. The cells shown in $\boldsymbol{E}$ and $\boldsymbol{G}$ were not recorded simultaneously.

VTA receive abundant GABAergic input from the basal ganglia, but the function of these long-range, inhibitory projections is unknown (Joel and Weiner, 2000; Tepper and Lee, 2007). In particular, it is unclear to what degree reward-related responses of neurons in the basal ganglia reflect and/or influence their dopaminergic input.
With these issues in mind, auditory responses of songbird dopaminergic neurons are intriguing in that they occur preferentially in response to a specific and complex sensory stimulus (BOS) that neither predicts primary reward nor is particularly novel in any obvious way, and because they appear to be driven by phasic, long-latency (typically $>100 \mathrm{~ms}$ ) disinhibition via basal ganglia input. What is the function of this disinhibition of dopaminergic neurons by the basal ganglia in songbirds?

One possible role of dopamine in the song system is to modulate song variability. Dopamine signaling could underlie social context-dependent differences in the trial-to-trial variability of song in adults, or modulate song variability that is crucial for song learning in juveniles. We discuss the former possibility first in considering the kinds of information dopaminergic neurons receive from area $\mathrm{X}$ or elsewhere as a bird sings.

Adult zebra finch song is highly stereotyped compared with plastic song in juveniles. Nonetheless, trial-to-trial song variability is slightly lower when males sing to a female (directed song) than when they sing alone (undirected song). Output from the AFP is necessary for this "residual" variability during undirected singing (Kao et al., 2005). Dopamine levels measured by microdialysis increase in area $\mathrm{X}$ during directed singing (Sasaki et al., 2006), and neural activity in the AFP is less variable during directed singing than undirected singing (Hessler and Doupe, 1999a). Hence, it is possible that females elicit dopamine release that reduces the variability of neural activity in the AFP and of song.

Dopamine release during directed singing would seem to require input to dopaminergic neurons pertaining to the female rather than motor- or auditoryrelated information about song. However, a rise in dopamine concentration in area $\mathrm{X}$ is detected when both a female is present and the male sings, but not when the male does not sing to the female or sings alone (Sasaki et al., 2006). This suggests that song-related motor or auditory activity, in addition to the female, contributes to increased dopamine release. An alternative explanation is that female-related cues act alone to increase dopamine levels in area $\mathrm{X}$, but the degree to which they do so correlates with how effectively the female motivates singing. Two additional observations argue that song-related input influences dopaminergic neurons. First, an increase in extracellular dopamine concentration is observed in area X during undirected singing if the dopamine reuptake transporter is blocked (Sasaki et al., 2006). Therefore 
singing, in the absence of a female, is sufficient to increase dopamine release, even though the magnitude or spatial-temporal pattern of this dopamine release is normally undetectable by microdialysis (Floresco et al., 2003; Venton et al., 2003; Phillips and Wightman, 2004). Second, the firing rate of many zebra finch VTA neurons (dopaminergic neurons not identified) changes during song, and some of these neurons increase their firing rate during specific song elements or milliseconds before song initiation (Yanagihara and Hessler, 2006). Thus, it appears that song-related input regulates the activity of dopaminergic neurons. We propose that this input comes, at least in part, from area $\mathrm{X}$ via VP.

Area $\mathrm{X}$ neurons increase their firing rate during singing and this increased firing is sustained for several hundred milliseconds after song (Hessler and Doupe, 1999b). Although singing-related activity of HVC neurons providing input to area $\mathrm{X}$ is not acutely affected by auditory-feedback perturbations, these same neurons are active during identical portions of BOS regardless of whether the bird is singing or hearing them (Kozhevnikov and Fee, 2007; Prather et al., 2008). Hence, singing-related activity in area $\mathrm{X}$ might reflect predicted, rather than real-time, auditory feedback (Troyer and Doupe, 2000). Some HVC neurons are sensitive to perturbed auditory feedback during singing and may eventually alter signals from HVC to area X (Sakata and Brainard, 2008). Processing of a "prediction" signal within the AFP and/or combining input to dopaminergic neurons from area $\mathrm{X}$ with auditory information from other pathways could allow dopaminergic neurons to signal the quality of song relative to some goal. This dopaminergic signal could regulate the overall variability of song or reinforce specific patterns of neural activity in the AFP that correlate with preferred vocal output (Kao et al., 2008; Andalman and Fee, 2009). We discuss these ideas further below.

Auditory responses of area X and other neurons in the AFP in anesthetized zebra finches suggest that input to dopaminergic neurons from area X might reflect feedback evaluation (regardless of where in the brain this evaluation is made). Some AFP neurons respond more or equally strongly to their tutor's song compared with BOS, even when these two songs are acoustically dissimilar (Solis and Doupe, 1999). Furthermore, BOS selectivity of AFP neurons is reduced when juvenile zebra finches are prevented from copying their tutor's song (Solis and Doupe, 2000). Thus, it is possible that area $\mathrm{X}$ transmits information related to how well BOS matches tutor song to dopaminergic neurons.

Dopaminergic neurons could also receive auditory information from neurons not activated by song playback in anesthetized birds. Some neurons in auditory regions of the telencephalon are sensitive to errors in predicted auditory feedback during singing (Keller and Hahnloser, 2009). These error signals might reach dopaminergic neurons via a projection to SNc/VTA from auditory regions of the arcopallium (Gale et al., 2008). Disinhibition of dopaminergic neurons by area X via VP would modulate the impact of input to dopaminergic neurons from this or any other pathway. Indeed, we cannot completely rule out that this occurs in anesthetized birds and contributed to auditory responses of dopaminergic neurons. An anatomical feedback loop including the VP in mammals has similarly been proposed to modulate sensory responses of dopaminergic neurons (Floresco et al., 2003; Lisman and Grace, 2005).

Why might area $\mathrm{X}$ output influence its dopaminergic input? Axon collaterals of area X pallidal-like neurons project to both VP and thalamus (DLM) (Fig. $1 A, B$ ), and thereby regulate both dopaminergic neurons and AFP output, respectively. These two target pathways respond to different features of their input from area X. Specifically, DLM neurons respond precisely via postinhibitory rebound to fine temporal features (rapid decelerations) of their input from a single area $\mathrm{X}$ afferent (Person and Perkel, 2005, 2007; Kojima and Doupe, 2009). In contrast, inhibition of $\mathrm{VP}$ and consequent disinhibition of dopaminergic neurons appears to be driven by the mean firing rate of input from area $\mathrm{X}$ over longer timescales (hundreds of milliseconds or greater). The overall excitation of area X pallidal-like neurons during song, perhaps influenced by song evaluation, could disinhibit dopamine release that gates long-term potentiation of input to area $\mathrm{X}$ spiny neurons (Fig. 1B) (Ding and Perkel, 2004). Plasticity of spiny neuron activity would shape the timing of brief pallidal-like neuron decelerations that drive DLM (and AFP) output. Over time, such a mechanism could be critical for reinforcing patterns of AFP activity that adaptively bias vocal output (Kao et al., 2008; Andalman and Fee, 2009). Area X-driven dopaminergic feedback to the song system may also have undetermined roles not related to reinforcement learning.

Much is still unknown about the function of the AFP and dopaminergic neurons with which it is connected. Regulation of the activity of dopaminergic neurons by a basal ganglia circuit critical for vocal learning is consistent with the possibility that dopaminergic neurons contribute to a broad range of motor learning in which goals or "rewards" are not immediately related to survival or reproduction.

\section{References}

Andalman AS, Fee MS (2009) A basal ganglia-forebrain circuit in the songbird biases motor output to avoid vocal errors. Proc Natl Acad Sci U S A 106:12518-12523.

Appeltants D, Absil P, Balthazart J, Ball GF (2000) Identification of the origin of catecholaminergic inputs to $\mathrm{HVc}$ in canaries by retrograde tract tracing combined with tyrosine hydroxylase immunocytochemistry. J Chem Neuroanat 18:117-133.

Appeltants D, Ball GF, Balthazart J (2002) The origin of catecholaminergic inputs to the song control nucleus RA in canaries. Neuroreport 13: 649-653.

Baker SN, Gerstein GL (2001) Determination of response latency and its application to normalization of cross-correlation measures. Neural Comput 13:1351-1377.

Bottjer SW (1993) The distribution of tyrosine hydroxylase immunoreactivity in the brains of male and female zebra finches. J Neurobiol 24:51-69.

Cameron DL, Wessendorf MW, Williams JT (1997) A subset of ventral tegmental area neurons is inhibited by dopamine, 5-hydroxytryptamine and opioids. Neuroscience 77:155-166.

Derégnaucourt S, Mitra PP, Fehér O, Pytte C, Tchernichovski O (2005) How sleep affects the developmental learning of bird song. Nature 433:710-716

Ding L, Perkel DJ (2002) Dopamine modulates excitability of spiny neurons in the avian basal ganglia. J Neurosci 22:5210-5218.

Ding L, Perkel DJ (2004) Long-term potentiation in an avian basal ganglia nucleus essential for vocal learning. J Neurosci 24:488-494.

Ding L, Perkel DJ, Farries MA (2003) Presynaptic depression of glutamatergic synaptic transmission by $\mathrm{D}_{1}$-like dopamine receptor activation in the avian basal ganglia. J Neurosci 23:6086-6095.

Dommett E, Coizet V, Blaha CD, Martindale J, Lefebvre V, Walton N, Mayhew JE, Overton PG, Redgrave P (2005) How visual stimuli activate dopaminergic neurons at short latency. Science 307:1476-1479.

Doupe AJ (1997) Song- and order-selective neurons in the songbird anterior forebrain and their emergence during vocal development. J Neurosci 17:1147-1167.

Doupe AJ, Kuhl PK (1999) Birdsong and human speech: common themes and mechanisms. Annu Rev Neurosci 22:567-631.

Farries MA, Perkel DJ (2002) A telencephalic nucleus essential for song learning contains neurons with physiological characteristics of both striatum and globus pallidus. J Neurosci 22:3776-3787.

Farries MA, Ding L, Perkel DJ (2005) Evidence for "direct" and "indirect" 
pathways through the song system basal ganglia. J Comp Neurol 484:93-104.

Fiete IR, Fee MS, Seung HS (2007) Model of birdsong learning based on gradient estimation by dynamic perturbation of neural conductances. J Neurophysiol 98:2038-2057.

Fiorillo CD, Newsome WT, Schultz W (2008) The temporal precision of reward prediction in dopamine neurons. Nat Neurosci 11:966-973.

Floresco SB, West AR, Ash B, Moore H, Grace AA (2003) Afferent modulation of dopamine neuron firing differentially regulates tonic and phasic dopamine transmission. Nat Neurosci 6:968-973.

Gale SD, Perkel DJ (2006) Physiological properties of zebra finch ventral tegmental area and substantia nigra pars compacta neurons. J Neurophysiol 96:2295-2306.

Gale SD, Person AL, Perkel DJ (2008) A novel basal ganglia pathway forms a loop linking a vocal learning circuit with its dopaminergic input. J Comp Neurol 508:824-839.

Green DM, Swets JA (1966) Signal detection theory and psychophysics. New York: Wiley.

Hessler NA, Doupe AJ (1999a) Social context modulates singing-related neural activity in the songbird forebrain. Nat Neurosci 2:209-211.

Hessler NA, Doupe AJ (1999b) Singing-related neural activity in a dorsal forebrain-basal ganglia circuit of adult zebra finches. J Neurosci 19:10461-10481.

Horvitz JC (2000) Mesolimbocortical and nigrostriatal dopamine responses to salient non-reward events. Neuroscience 96:651-656.

Horvitz JC, Choi WY, Morvan C, Eyny Y, Balsam PD (2007) A "good parent" function of dopamine: transient modulation of learning and performance during early stages of training. Ann N Y Acad Sci 1104:270-288.

Joel D, Weiner I (2000) The connections of the dopaminergic system with the striatum in rats and primates: an analysis with respect to the functional and compartmental organization of the striatum. Neuroscience 96:451-474.

Kao MH, Doupe AJ, Brainard MS (2005) Contributions of an avian basal ganglia-forebrain circuit to real-time modulation of song. Nature 433:638-643.

Kao MH, Wright BD, Doupe AJ (2008) Neurons in a forebrain nucleus required for vocal plasticity rapidly switch between precise firing and variable bursting depending on social context. J Neurosci 28:1323213247.

Keller GB, Hahnloser RH (2009) Neural processing of auditory feedback during vocal practice in a songbird. Nature 457:187-190.

Kojima S, Doupe AJ (2009) Activity propagation in an avian basal gangliathalamocortical circuit essential for vocal learning. J Neurosci 29: 4782-4793.

Kozhevnikov AA, Fee MS (2007) Singing-related activity of identified HVC neurons in the zebra finch. J Neurophysiol 97:4271-4283.

Leblois A, Bodor AL, Person AP, Perkel DJ (2009) Millisecond timescale disinhibition mediates fast information transmission through an avian basal ganglia loop. J Neurosci 29:15420-15433.

Lewis JW, Ryan SM, Arnold AP, Butcher LL (1981) Evidence for a catecholaminergic projection to area $\mathrm{X}$ in the zebra finch. J Comp Neurol 196:347-354.

Lisman JE, Grace AA (2005) The hippocampal-VTA loop: controlling the entry of information into long-term memory. Neuron 46:703-713.

Luo M, Perkel DJ (1999) Long-range GABAergic projection in a circuit essential for vocal learning. J Comp Neurol 403:68-84.

Margoliash D (1983) Acoustic parameters underlying the responses of song-specific neurons in the white-crowned sparrow. J Neurosci 3:10391057.

Margolis EB, Hjelmstad GO, Bonci A, Fields HL (2003) $\kappa$-Opioid agonists directly inhibit midbrain dopaminergic neurons. J Neurosci 23:99819986.

Margolis EB, Lock H, Hjelmstad GO, Fields HL (2006) The ventral tegmental area revisited: is there an electrophysiological marker for dopaminergic neurons? J Physiol 577:907-924.
Meitzen J, Moore IT, Lent K, Brenowitz EA, Perkel DJ (2007) Steroid hormones act transsynaptically within the forebrain to regulate neuronal phenotype and song stereotypy. J Neurosci 27:12045-12057.

Ölveczky BP, Andalman AS, Fee MS (2005) Vocal experimentation in the juvenile songbird requires a basal ganglia circuit. PLoS Biol 3:e153.

Pan WX, Hyland BI (2005) Pedunculopontine tegmental nucleus controls conditioned responses of midbrain dopamine neurons in behaving rats. J Neurosci 25:4725-4732.

Person AL, Perkel DJ (2005) Unitary IPSPs drive precise thalamic spiking in a circuit required for learning. Neuron 46:129-140.

Person AL, Perkel DJ (2007) Pallidal neuron activity increases during sensory relay through thalamus in a songbird circuit essential for learning. J Neurosci 27:8686-8698.

Person AL, Gale SD, Farries MA, Perkel DJ (2008) Organization of the songbird basal ganglia, including area X. J Comp Neurol 508:840-866.

Phillips PE, Wightman RM (2004) Extrasynaptic dopamine and phasic neuronal activity. Nat Neurosci 7:199.

Phillips PE, Stuber GD, Heien ML, Wightman RM, Carelli RM (2003) Subsecond dopamine release promotes cocaine seeking. Nature 422:614618.

Pinault D (1996) A novel single-cell staining procedure performed in vivo under electrophysiological control: morpho-functional feature of juxtacellularly labeled thalamic cells and other central neurons with biocytin or Neurobiotin. J Neurosci Methods 65:113-136.

Prather JF, Peters S, Nowicki S, Mooney R (2008) Precise auditory-vocal mirroring in neurons for learned vocal communication. Nature 451: 305-310.

Redgrave P, Gurney K, Reynolds J (2008) What is reinforced by phasic dopamine signals? Brain Res Rev 58:322-339.

Sasaki A, Sotnikova TD, Gainetdinov RR, Jarvis ED (2006) Social contextdependent singing-regulated dopamine. J Neurosci 26:9010-9014.

Scharff C, Nottebohm F (1991) A comparative study of the behavioral deficits following lesions of various parts of the zebra finch song system: implications for vocal learning. J Neurosci 11:2896-2913.

Schultz W (1998) Predictive reward signal of dopamine neurons. J Neurophysiol 80:1-27.

Solis MM, Doupe AJ (1997) Anterior forebrain neurons develop selectivity by an intermediate stage of birdsong learning. J Neurosci 17:6447-6462.

Solis MM, Doupe AJ (1999) Contributions of tutor and bird's own song experience to neural selectivity in the songbird anterior forebrain. J Neurosci 19:4559-4584.

Solis MM, Doupe AJ (2000) Compromised neural selectivity for song in birds with impaired sensorimotor learning. Neuron 25:109-121.

Tepper JM, Lee CR (2007) GABAergic control of substantia nigra dopaminergic neurons. Prog Brain Res 160:189-208.

Theunissen FE, Doupe AJ (1998) Temporal and spectral sensitivity of complex auditory neurons in the nucleus $\mathrm{HVc}$ of male zebra finches. J Neurosci 18:3786-3802.

Theunissen FE, Amin N, Shaevitz SS, Woolley SM, Fremouw T, Hauber ME (2004) Song selectivity in the song system and in the auditory forebrain. Ann N Y Acad Sci 1016:222-245.

Troyer TW, Doupe AJ (2000) An associational model of birdsong sensorimotor learning. I. Efference copy and the learning of song syllables. J Neurophysiol 84:1204-1223.

Ungless MA, Magill PJ, Bolam JP (2004) Uniform inhibition of dopamine neurons in the ventral tegmental area by aversive stimuli. Science 303:2040-2042.

Venton BJ, Zhang H, Garris PA, Phillips PE, Sulzer D, Wightman RM (2003) Real-time decoding of dopamine concentration changes in the caudateputamen during tonic and phasic firing. J Neurochem 87:1284-1295.

Wise RA (2004) Dopamine, learning, and motivation. Nat Rev Neurosci 5:483-494.

Yanagihara S, Hessler NA (2006) Modulation of singing-related activity in the songbird ventral tegmental area by social context. Eur J Neurosci 24:3619-3627. 